\title{
Exploration of New Model of University Laboratory Construction and Management
}

Xinying Wang

Henan Province Pingdingshan University, Pingdingshan 467000, Henan, China.

Abstract: The laboratory is an important place for students to conduct basic experiments and schools to conduct scientific research, and is an important infrastructure project for colleges and universities. Based on the current status of university construction, this article conducts research and exploration on the construction and management of university laboratories, so as to promote the further improvement of university laboratories, provide students with a better practice and innovation platform, and comprehensively enhance students' basic scientific research capabilities.

Keywords: University Laboratory; Construction Management; Model Exploration

In the traditional management concepts of many colleges and universities, there are problems of "emphasis on construction, light management, heavy hardware and light software" in laboratory construction, which makes the progress of university laboratory construction slow, and there are many management problems and waste of resources, which seriously restrict The quality of university laboratory expansion and innovative talent training. Combining many years of laboratory management experience in colleges and universities, the author analyzes the current situation of laboratory construction and management in colleges and universities from the actual situation, and proposes some effective measures to improve the quality and management efficiency of laboratory construction, in order to provide students with a better scientific practice Platform to improve the scientific practice ability of college students.

\section{Current situation of university laboratory construction and management}

\subsection{Lack of overall planning for laboratory construction}

With the increasing number of scientific research projects that universities need to carry out and the need for more and more new experimental equipment, this has brought great financial pressure to schools, but some universities do not recognize the status quo and lack an overall understanding of the laboratory. Planning and blindly launching new projects and new equipment will reduce the utilization rate of new equipment after the experiment is completed, resulting in a huge waste of resources.

\subsection{Laboratory management is relatively scattered}

"Emphasis on construction and light on management" is a common problem in many colleges and universities at present, because laboratories basically conduct scientific experiments, and the relevant persons in charge lack certain management experience, and basically focus on experimental projects, making the laboratory Management is relatively scattered, and this situation will become increasingly prominent with the expansion of the laboratory, which is very unfavorable for the subsequent development of the laboratory.

\subsection{Laboratory technicians are less efficient}

Because university laboratories are not strict in terms of technical results requirements, coupled with loose management, internal technicians lack a sense of work urgency, and the overall performance is low in work efficiency and slow in improving

This is an open-access article distributed under the terms of the Creative Commons Attribution Non-Commercial License (http://creativecommons. org/licenses/by-nc/4.0/), which permits unrestricted non-commercial use, distribution, and reproduction in any medium, provided the original work is properly cited. 
professional capabilities. Coupled with the shortage of laboratory funds and the limited salary of technicians, the technicians lack work enthusiasm, and the overall laboratory atmosphere is very depressing.

\section{Exploration of the new model of university laboratory construction and management}

\subsection{Laboratory construction planning and principles}

First of all, in the construction of various types of laboratories in colleges and universities, the construction of laboratories related to student teaching should be put in the first place, first to meet the basic experimental needs of students, and then to consider further upgrades after meeting the basic needs. Secondly, while planning for the construction of basic laboratories, space and funds should be reserved for the construction of professional laboratories, high-quality scientific research projects should be selected as breakthrough points, and funds should be concentrated to do practical work. Third, the construction of college laboratories should be adapted to the actual teaching situation and scope of the school, and the counterpart laboratories should be built according to the school's subject advantages, so as to give full play to the advantages of college subject scientific research. Fourth, laboratory construction should pay attention to building a good laboratory environment. In addition to the basic hardware facilities, the laboratory should be kept clean and orderly, and the internal decoration of the laboratory should be systematically planned, and strive to present a good academic atmosphere, which is conducive to improving the work efficiency of technical personnel. Finally, attention should be paid to the construction of a team of experimental technicians. The laboratory is not only experimental equipment, but also technical personnel who use the equipment. Therefore, in order to better complete experimental projects, improve experimental quality and efficiency, and maximize scientific research output, it should also actively cultivate outstanding technical personnel and improve The enthusiasm of technical staff to promote the further improvement of the laboratory.

\subsection{Exploration of laboratory management mode}

In reforming the laboratory management system, the focus of attention is to solve the problems of scattered management, overlapping projects, waste of funds and overly closed laboratories in the current management system.

First of all, the laboratory should adopt a centralized management model. Many university laboratory management systems are too scattered, which easily leads to unclear responsibilities and unclear tasks. Therefore, universities should implement the laboratory director responsibility system to coordinate the construction and management of the laboratory and effectively improve the efficiency of laboratory construction.

Secondly, all experimental projects need to be carefully reviewed. University laboratories should set up special project review teams to conduct strict review of different experimental projects, eliminate suspected overlapping projects, concentrate resources as much as possible to make breakthroughs in high-quality projects, and increase the ratio of laboratory research output.

Finally, make full use of laboratory resources and limited open laboratories. University laboratories should play their comprehensive role. They should not only serve students' teaching experiments, but should also provide limited openness to students in their spare time. This not only avoids the waste of laboratory resources, but also cultivates students' initiative to discover Problem, problem analysis and problem-solving ability, effectively improve students' scientific research and innovation ability.

\section{Conclusion}

In summary, the construction of a good laboratory is the basic condition for the development of universities. Universities should carry out targeted reforms based on the prominent problems in laboratory development, starting with laboratory construction and laboratory management, and closely focusing on student practice Ability and innovation ability training, strengthen the laboratory management system, establish a complete, orderly, and efficient laboratory environment, effectively improve the scientific research and technical capabilities of university laboratories, and cultivate more outstanding scientific research and technical personnel.

\section{References}

1. Li NW, Bai WD, Liu GL, et al. Exploration of a new model of laboratory construction and management in colleges and universities. Guangdong Chemical Industry 2017; 044(004): 135, 144.

2. Chen $\mathrm{ZL}, \mathrm{Xu} \mathrm{SN}$, Wang J, et al. Exploration and thinking of laboratory construction and management mode in colleges and universities. Laboratory Science 2012; 15(002): 122-125.

3. Li GR. Analysis on the exploration and application of the new model of laboratory management. Journal of Chifeng University (Natural Edition) 2012; (15): 232-233. 